\title{
Comics Polysystem in Iran: A Case Study of the Persian Translations of Les Aventures de Tintin
}

Despite the popularity of comics, the subject of their translation has remained notably underexplored. Comics swept into the market of Iran in the 1970s; however, they were a new and unfamiliar genre in the country. One of the earliest comic series to appear in Iran was Les Aventures de Tintin, translated by Khosro Sami'i and published by Universal Publications before the Islamic Revolution of Iran in 1979. Following the Revolution, Universal discontinued the series in Iran and other publishers briefly took it up; after a few years, publication of the books was discontinued. It was not until 2000 that the series was re-introduced by Tarikh-o Farhang and Andishe-ye No Publications. Moreover, as a result of the ubiquitous availability of comic books on the Internet, scanlations made by Tintinophiles have burgeoned recently. This study examines the translations into Persian of Les Aventures de Tintin from these three groups (the early editions of the 1970s and 1980s, the revived publications of 2000, and the Internet scanlations) and attempts to shed light on the position of comics in the translated polysystem of Iran. For this purpose, Even-Zohar's Polysystem theory ("Polysystem Studies" 9-26) and Tamaki's approach (119-146) are employed. The synthetic model of translation description proposed by Lambert and Van Gorp (42-53) is used to examine the translations in three layers: 1) preliminary data, 2) macro-level, and 3) micro-level. Onomatopoeic representations are analysed at the micro-level to investigate the extent to which their translations have broken target culture norms and conventions. The results of the study reveal a gap for comics, an empty niche to be filled, in the translated polysystem of Iran and, accordingly, a canonized position for this genre and its translations. This position, however, has migrated to a less central place in more recent translations. 